\title{
GABRIELA MISTRAL Y LA LITERATURA RUSA. UINA APROXIMACIÓN A LA INFLUENCIA DE LEV TOLSTÓI, MÁXIMO GORKI Y LEONID ANDREIEV EN SU VIDA Y OBRA (1904-1936)
}

\author{
GABRIELA MISTRAL AND RUSSIAN LITERATURE. \\ ON THE INFLUENCE OF LEO TOLSTOY, \\ MAXIM GORKI AND LEONID ANDREIEV ON HER \\ LIFE AND WORK (1904-1936)
}

\author{
GABRIELA MISTRAL E A LITERATURA RUSSA. \\ UMA APROXIMAÇÃO À INFLUÊNCIA DE LEV \\ TOLSTOI, MÁXIMO GORKI E LEONID ANDREIEV \\ EM SUA VIDA E SUA OBRA (1904-0936)
}

Alfredo Gorrochotegui Martell*

RESUMEN

En este artículo se trata de explicar la influencia de algunos novelistas rusos en la vida y obra de Gabriela Mistral, ya que en su existencia artística son nombrados con cierta frecuencia, además de recomendarlos como lectura obligatoria, citándolos para referirse a ellos como ejemplo para la educación y el cambio social. En un primer momento, se describe y analiza la influencia de estos autores, a finales del siglo XIX y principios del XX en Chile, a través de hitos significativos como: el primer encuentro

* Doctor en Educación, 1995. Universidad de los Andes. Chile. Este artículo es parte de la investigación "Gabriela Mistral directora de escuela. Su servicio a la educación pública chilena (1912-1922)", que está en desarrollo. Instituto de Historia.

Correo electrónico: agorrochotegui@uandes.cl; agorro@gmail.com.

http://orcid.org/0000-0002-7726-7331.

Artículo recibido el 26 de mayo de 2016 y aprobado para su publicación el 10 de agosto de 2016. 
que, gracias a la biblioteca de Bernardo Ossandón, Mistral tuvo con estos en 1904; la recomendación que Mistral hizo a Neruda sobre su lectura en 1920; y algunos escritos posteriores en prosa, entrevista y diarios íntimos donde se refiere a ellos. En un segundo momento, se intenta mostrar cómo algunos novelistas rusos no son solo inspiración literaria para Mistral, sino personas con las que se identifica plenamente, por las coincidencias que observa entre estos y ella misma, en el ámbito de los sufrimientos, dificultades y carencias, que se dan a lo largo de sus vidas

\title{
PALABRAS CLAVE
}

Gabriela Mistral, Novelistas rusos, Escritores chilenos, Influencia literaria, Influencia biográfica.

\begin{abstract}
The purpose of the article is to explain the influence of some Russian novelists on Gabriela Mistral's life and work, because those are frequently mentioned during her artistic career, recommended as mandatory readings, and quoted as referents for education and social change. Firstly, the influence of those writers is described and analyzed, based on significant moments during the end of the $19^{\text {th }}$ century and the beginning of the $20^{\text {th }}$ century: her first contact with the works of those writers in 1904 in Bernardo Ossandón's Library, the suggestion to read them made to Neruda in 1920, and some writings, interviews, and journals in which she mentioned them. Secondly, it is intended to show how some Russian novelists were not only a literary influence on Mistral, but also people with whom she strongly identified herself, due to the similarities she seemed to recognize; such as the sufferings and difficulties experienced during their lives.
\end{abstract}

\section{KEY WORDS}

Gabriela Mistral, Russian Novelists, Chilean Writers, Literary Influences, Biographical Influences.

\section{RESUMO}

Este artigo tenta explicar a influência de alguns romancistas russos na vida e na obra de Gabriela Mistral, posto que na sua existência artística são nomeados com frequência e, além, disso os recomenda como leitura obrigatória, referindo-os como exemplo para a educação e o câmbio social. Em um primeiro momento, descreve-se e analisa-se a influência desses autores, no fim do século XIX e no começo do XX no Chile, por meio de acontecimentos significativos como: o primeiro encontro que teve Mistral com esses autores graças à biblioteca de Bernardo Ossandón, em 1904; a recomendação que Mistral fez a Neruda sobre a leitura deles em 1920; e, alguns escritos posteriores em prosa, entrevista e diários íntimos onde se refere a eles. Em um segundo momento, tenta-se mostrar como alguns romancistas russos não são apenas inspiração literária para Mistral, mas pessoas com que se identifica plenamente, pelas coincidências que observa entre eles e ela mesma, no âmbito dos sofrimentos, dificuldades e carências, que se dão ao longo de suas vidas.

\section{PALAVRAS-CHAVE}

Gabriela Mistral, Romancistas rusos, Escritores chilenos, Influência literaria, Influência biográfica. 


\section{Introducción}

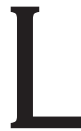

a literatura rusa ha sido considerada una de las más extraordinarias producciones artísticas de corte universal. Sus obras han sido leídas y traducidas en el mundo occidental. Un aspecto clave a considerar es que su origen está asentado en "un pueblo sin precedentes en la historia de la humanidad; es muy natural, por lo tanto, que las manifestaciones de su espíritu, en cualquier rama de las bellas artes, sean originales y sigan caminos propios, fuera de las vías tradicionales de la cultura occidental" (Schostakovsky 7). Una manifestación artística de un sector de la humanidad con este nivel de importancia, calidad y originalidad, tiene que haber dejado huella imborrable en cantidad ingente de artistas a lo largo y ancho del planeta. Gabriela Mistral (1889-1957) no es una excepción.

Su vida transcurrió y maduró, sufrió y triunfó a la sombra de sus lecturas. $\mathrm{Y}$ entre estas, como veremos, algunos autores rusos tuvieron un papel importante, no solo como inspiradores para escribir, sino también como espejos donde mirarse, pues muchos de ellos también pasaron por momentos difíciles en sus propias vidas y en sus relaciones sociales, políticas y artísticas.

Hemos descubierto que en algunos momentos de la vida de Gabriela Mistral, como en sus escritos, diarios íntimos y en sus relaciones con otros artistas, algunas sugerencias que hace la poeta sobre la lectura de novelistas rusos. Incluso, mucho más adelante, cuando tiene fama, en alguna entrevista deja entrever no solo la gran influencia que tuvieron en ella, sino también esa especie de identificación de sus sufrimientos, "tortura interior" lo llamará, con los sufrimientos de estos escritores.

Por tanto, para guiar esta investigación, intentaremos responder a la siguiente pregunta: cंqué relación existe o ha existido entre los escritos de algunos novelistas rusos y la vida y obra de Gabriela Mistral? No pretendemos con esto dar una explicación total de todos los detalles de esa relación. Al contrario, solo nos aproximaremos, especialmente, a los momentos en los que, por ahora, sabemos que comentó a estos 
novelistas. En una artista de la talla de Mistral es importante dilucidar con quiénes se identificó y qué influencia dejaron y le permitieron ser la mujer y la artista que fue.

Este artículo se estructura en cuatro partes: la primera se refiere a la influencia que pudieron haber tenido algunos novelistas rusos en la literatura y en la sociedad chilena de principios del siglo XX. La segunda, se centra en el encuentro inicial de Gabriela Mistral y los novelistas rusos durante su adolescencia. La tercera parte, se refiere al importante encuentro con Pablo Neruda, en el que Mistral lo marca para toda la vida recomendándole que lea a estos escritores; el poeta siempre se lo agradecerá. La cuarta y última parte, la más extensa, se aboca al análisis de distintos escritos, entrevistas y un diario íntimo, en los que la poeta los cita, sugiere sus lecturas y da a conocer su amplio conocimiento sobre estos. También se analizan los novelistas que más comenta o de los que hace alguna acotación claramente reveladora sobre su influencia ideológica e incluso psicológica. Hablaremos, por tanto, de la especial relación de Mistral con Lev Tolstói, Máximo Gorki y Leonid Andreiev ${ }^{1}$.

\section{Los novelistas rusos en la literatura y la sociedad chilena. Principales influencias}

El estudioso Domingo Melfi ha señalado que los escritores chilenos nacidos a finales del siglo XIX, conocidos a principios del XX, y en cuyos dos primeros lustros mostraron sus obras más renombradas, fueron influidos directamente por algunos literatos rusos. Destaca, entre estos, a Tolstói, Gorki y Dostoievski y señala que: “[...] todos estos autores europeos [...] habían entrado en Chile en los últimos años del siglo anterior, en los libros y revistas, a través de los bosques cordilleranos o en los vapores que atracaban en los puertos. Ellos derramaron sobre la plácida vida chilena [...] la visión concreta y trágica de la existencia" (72).

1 Para los nombres de los autores rusos hemos intentado seguir las reglas sugeridas por la RAE. Sin embargo, se mantiene la ortografía, a veces distinta, con que son nombrados dichos autores en ediciones que se citan textualmente y que no siguen las actuales reglas de la Academia. 
Los chilenos, continúa el autor, que leían a estos escritores a principios de siglo, "levantaban la cabeza del libro descubrían la mentira del mundo que les rodeaba" (73). Y luego concluye que: "todos los escritores rusos [...] produjeron como un deslumbramiento en la generación del 900” (75).

A todos estos literatos europeos que, a través de sus obras, llegaron al continente suramericano de entonces, también españoles, italianos y franceses, se les califica como los representantes de la narrativa social europea. Ellos traen el influjo del naturalismo y el realismo en su máxima expresión. El investigador Jaime Galgani describe este hecho como la llegada de la novela social a Chile. Plantea el hecho de que la recepción de estos escritores europeos selló el panorama de la producción escritural. Se trata, pues, de una literatura que llega a los cenáculos, tertulias, ateneos, salones y revistas literarias a partir de 1880, impactando a intelectuales, lectores y escritores chilenos (Galgani, "Recepción" 16).

Lo anterior va a producir lo que Galgani llama la aparición de escritores de nuevo cuño, desvinculados de funciones políticas o de élites económicas:

Su ejercicio literario estará vinculado más bien a una creciente profesionalización del oficio, y, sobre todo, a también crecientes grados de autonomía con respecto a los campos dominantes. Esta nueva situación del escritor, que corresponde, en términos generales, al proceso de especialización inaugurado por la modernidad, permitirá generar, como rasgo específico suyo, un tipo de creación literaria que destacará por su posicionamiento crítico frente a diversas instancias que nuclean las bases estructurantes del poder. Representan este modelo nombres de escritores como Baldomero Lillo, Luis Orrego Luco, Augusto D’Halmar, Joaquín Edwards Bello, Manuel Rojas, Gabriela Mistral, Pablo Neruda, etc. (“Recepción” 18).

Un ejemplo concreto de este nuevo movimiento de escritores chilenos influidos por los literatos europeos, y dentro de estos, especialmente por los rusos, es la aparición de La Colonia Tolstoyana². Esta experiencia

2 En este artículo hemos preferido enfocarnos en la Colonia Tolstoyana y no en otra que se denominó Colonia Pio Nono, por la calle donde comenzó sus actividades, o simplemente "La otra colonia". Es poco lo que se ha estudiado sobre esta otra colonia, y pocos son los documentos que tratan de ella. Tenía el mismo espíritu, pero sus actividades tenían mayor relación con las ideas revolucionarias de Tolstói, Kropotkin, Reclus, Marx y Engels, entre 
"trató de emular el proyecto misionero de León Tolstói, el cual se proponía mejorar la calidad de vida de los campesinos rusos. Con este propósito, hacia 1904 se reunió un grupo de escritores jóvenes y artistas en Santiago, dirigidos por Augusto D’Halmar" (Domínguez 41-42). Aunque algunos autores opinan que La Colonia fue más bien "una síntesis de las pugnas literarias y culturales que aparecen tímidamente a inicios del siglo XX" (Galgani, "La Colonia" 56), también "expresó el deseo de idealidad de la juventud artística y creadora de la época" (Tzitsikas 14). Constituyó -La Colonia Tolstoyana- el resultado concreto de poner en práctica las ideas de uno de los novelistas y pensadores sociales rusos del momento, en un siglo de cambios radicales, angustias y desorientación en el campo político y cultural. En este mismo sentido, concluye Galgani, La Colonia "[...] vale como una experiencia señera que recoge un pequeño núcleo de la generación de 1900 y que representa los intereses de una época en que aún no era posible discernir el valor de los influjos artísticos procedentes especialmente de Europa" (Galgani, "La Colonia" 67).

Independientemente de la escasa duración que tuvo esta experiencia, y como resultado de los desencuentros entre sus miembros ${ }^{3}$, podríamos leer lo que uno de ellos dice de sí mismo frente a su encuentro con la literatura rusa, lo que muestra a todas luces el fuerte influjo de esta en los círculos literarios de entonces. Lo que expresa Fernando Santiván a continuación, lo escribe en una obra suya dedicada a explicar su experiencia en La Colonia Tolstoyana. Como antecedente a su participación en La Colonia, cuenta lo que le pasó al entrar en la biblioteca de su entonces Escuela de Artes y Oficios:

otros. Su objetivo era más social y político. Estaba configurada no por artistas literarios sino por personas de oficios diversos como zapateros, tipógrafos, tapiceros, empastadores de libros, joyeros o comerciantes de la vega. También participaron algunos obreros franceses anarquistas que habían llegado al país en esos tiempos. La mayoría de ellos vivía con sus mujeres y sus hijos. Además, la colonia era visitada por obreros e intelectuales que estuvieron ligados al desarrollo del movimiento obrero chileno. Un estudio interesante sobre lo poco que se sabe de esta colonia se puede conseguir en: Rioseco, Juan, "Utopía y Comunidad: Dos proyectos de vida comunitaria a comienzos del siglo XX en Chile". Revista Pléyade. 5 (2015): 93-112.

3 Este desencuentro entre los componentes de la Colonia está bastante bien explicado en el artículo de Galgani "La Colonia" que hemos venido citando. 
En la biblioteca de la escuela había algunas obras de escritores rusos. Las palabras sencillas de estos hombres atormentados, de una finura y distinción de espíritu que no tiene paralelo en la literatura mundial, fueron como una amplificación majestuosa de la angustia metafísica que había hecho presa en mi espíritu. Nunca una semilla cayó en suelo más blando, esponjoso, propicio para contribuir a su desarrollo (Santiván 87).

El anterior ambiente cultural será reconfirmado por el escritor Fernando Alegría, quien subraya que en esa época la intelectualidad chilena se revolucionaba al contacto del socialismo y misticismo de los rusos. Y como biógrafo de Mistral también aseverará que esta "no le perdía el paso a Santiván, a Pedro Prado, a D’Halmar, a Magallanes Moure, aprendices todos de Yasnaia Poliana" (Alegría 31).

Es en este contexto nacional en el que Gabriela Mistral tiene su encuentro con los rusos, a los que jamás dejará. Su contacto con estos escritores no es fortuito. Da con ellos, al igual que Santiván, en una biblioteca. Pero en su caso, en una biblioteca privada, de un intelectual de Coquimbo, como veremos más adelante. Esto indica que la literatura rusa permeó la vida intelectual y cultural de Chile de finales del siglo XIX y principios del XX, imprimiendo en los artistas y escritores un estilo distinto a los de sus predecesores. Y a la vez, la lectura de estos "hombres atormentados", como los calificara Santiván, iban a servir de ejemplo a manera de seres humanos que sufrieron por sus intrincadas circunstancias personales, y por los sucesos propios de un cambio radical de época, como lo fue el cambio de siglo, entre el XIX y el XX.

\section{El encuentro con los novelistas rusos: 1904}

Gabriela Mistral vive en un tiempo en que el estado chileno hace grandes esfuerzos por extender la educación, labor que viene procurando desde 1840, pero que se afianza hacia finales del siglo XIX y principios del XX (Mayorga 11-44; Ponce de León 449-486). Ante las grandes carestías de entonces, especialmente en el mundo rural, los fondos destinados a la educación aumentan convirtiendo a este sector "como el ramo de mayor 
trascendencia dentro de las funciones sociales del estado" (Serrano, Ponce de León y Rengifo 66). Es destacable, por ejemplo, que "sólo entre 1900 y 1910 se abrieron 1.252 escuelas, más de lo que se había fundado en los cincuenta años anteriores" (66).

Es un tiempo de lucha contra el analfabetismo. El Censo General de 1907 arrojaba que el 51,6\% de los mayores de cinco años sabía leer, pero el número de analfabetos seguía muy alto. De hecho, "una de cada tres personas analfabetas era un niño" (Serrano, Ponce de León y Rengifo 66). Igualmente, el mismo Censo muestra que para 1907, "el 31,9\% de la población escolar estaba matriculada en una escuela primaria, y de ella sólo asistía el $61 \%$. Es decir, nada más el $17 \%$ de los niños de Chile llegaban a una escuela" (Serrano, Ponce de León y Rengifo 64). Pero, por otro lado, la educación de la mujer también tuvo logros, pues, aunque su incorporación tardó varios años, "su alza fue vertiginosa al iniciarse el nuevo siglo, lo que además coincidió con la apertura de nuevos liceos femeninos" (Serrano, Ponce de León y Rengifo 69). Estamos en una época en que ser educador, por tanto, tiene una relevancia novedosa. Es en este tiempo en el que Gabriela Mistral conoce a los novelistas rusos.

En 1904, Mistral es una quinceañera que se encuentra ante un año lleno de múltiples coincidencias para su vida futura: comienza a trabajar directamente en la labor educacional. Se inicia siendo ayudante preceptora en "La Compañía Baja", a las afueras de la Serena, en Coquimbo (Zegers 17). Ya en esa labor, muestra su sensibilidad social cuando enseña a leer a alumnos que tienen de cinco a diez años y a muchachos analfabetos que la sobrepasan en edad (Mistral, Antología de poesía 391).

1904 es el año en que Mistral publica su primera producción literaria en el periódico El Coquimbo. Es el 11 de agosto, y su artículo se llama "El perdón de una víctima", el cual firma con su verdadero nombre, Lucila Godoy (Zegers 44). Pero no solo esto. En 1904 nace Pablo Neruda; más adelante leeremos su testimonio en relación a la influencia que Mistral tuvo en él al invitarlo a leer a los novelistas rusos. En 1904, asimismo, muere uno de los más grandes cuentistas rusos, Antón Chejov, autor que es nombrado por Neruda como uno de los que la propia Mistral le invitó a leer. 
También es en 1904, como hemos analizado más arriba, cuando Augusto D’Halmar, junto a Santiván y Ortiz de Zárate fundan en Chile La Colonia Tolstoyana, experiencia que intenta emular la propuesta de Tolstói acerca de la educación y la vida apacible y sencilla del campo y que en su momento llamó la atención y la crítica de varios intelectuales del país (Galgani, "La Colonia" 62-65).

$\mathrm{Y}$ es, finalmente, en ese mismo año, en que se produce el encuentro de Gabriela Mistral con los artistas rusos. Un periodista y educador de nombre Bernardo Ossandón "[...] le prestó los libros que la convirtieron en una verdadera autodidacta, con su lectura diaria vesperal y nocturna" (Ocampo 225). Este dato aparece en un documento que la misma Gabriela Mistral escribe en 1949 intitulado "El oficio lateral", siendo ella Cónsul de Chile en México. De hecho, el documento está mecanografiado sobre una hoja timbrada con la palabra "Consulado de Chile":

\begin{abstract}
Empecé a trabajar en una escuela de la aldea llamada «Compañía Baja» [...] A la aldea también le había agradado poco el que le mandasen una adolescente para enseñar en su Escuela. Pero el pueblecito con mar próximo y dueño de un ancho olivar a cuyo costado estaba mi cama, me suplía la falta de amistades [...] Un viejo periodista dio un día conmigo o yo di con él. Se llamaba Don Bernardo Ossandón y poseía el fenómeno provincial de una biblioteca grande y óptima. No entiendo cómo el señor me abrió su tesoro, fiándome libros de buenas pastas y de papel fino [...] Con esto comienza para mí el deslizamiento hacia la fiesta pequeña y clandestina que sería mi lectura vesperal y nocturna, refugio que se me abriría para no cerrarse más (Mistral, $E l$ oficio lateral 1$)$.
\end{abstract}

Siguiendo el mismo documento citado, descubrimos que Gabriela Mistral ofrece pormenores de qué fue lo leído en esa biblioteca: "El bondadoso hombre Ossandón me prestaba a manos llenas libros que me sobrepasaban [...] varias biografías formativas y encendedoras (sic) [...] un Montaigne, donde me halló por primera vez delante de Roma y Francia..." (1-2). Luego, nuestra escritora hace un giro en forma de reclamo a sus compatriotas que, al parecer, se burlan de alguna de sus lecturas juveniles, entre las que están los escritos del colombiano Vargas Vila. Pero es allí cuando hace la declaración que estamos buscando. Dice 
así: "[...] pero esos mismos que me dan al tropical [-se refiere aquí a Vargas Vila-] como mi único entrenador pudiesen nombrar también a los novelistas rusos que varios de ellos aprovecharon en mis estantitos" (Mistral, El oficio lateral 2).

Rolando Manzano, especialista sobre los años en que Gabriela vivió en Coquimbo, nos relata que esta relación pudo haber comenzado cuando la joven profesora de La Compañía Baja se acercó a Don Bernardo como propietario del periódico El Coquimbo para solicitarle le publicara sus escritos, a lo cual accedió sin problemas. Esto pudo haber ocurrido en el primer semestre de 1904. Pero también juzga este autor que "normalmente se ha dicho, siguiendo a Gabriela, que le facilitó libros de su biblioteca, o que puso a su disposición su biblioteca personal, pero probablemente haya ido un poco más lejos, y a parte de sus propios libros, le haya facilitado el acceso a la biblioteca del Club Coquimbo que pertenecía a la Logia, de la cual era miembro..." (Manzano 109-110).

Como ya hemos indicado antes, era bastante posible encontrar en la biblioteca de un intelectual de la talla de Ossandón, propietario de un periódico y destacado educador y actor social y político de la región, autores que fuesen leídos por quienes intentaban estar al día en las novedades de la literatura universal (Pavez 1-2; Fuentes 49-50).

Es en ese lugar y ambientes donde Gabriela Mistral comienza a tener contacto con los escritores rusos. No serán los únicos. También habla de su encuentro, en ese mismo documento, con Rubén Darío, Amado Nervo y Leopoldo Lugones (Mistral, El oficio lateral 2). Pero no hay duda de que es en estos instantes donde comienza esa aventura con los rusos que jamás la dejará4.

4 Un dato interesante sobre el temprano conocimiento de los novelistas rusos, lo ofrece la misma Gabriela Mistral hablando de una de sus experiencias como maestra en La Cantera, cerca de Coquimbo, hacia el ańo 1908. Sobre su contacto con los campesinos de ese lugar, nos relata: "Yo hacía con ellos el desgrane del maíz contándoles cuentos rusos y les oía los suyos". En: Mistral, Gabriela. Vivir y escribir. Prosas autobiográficas. Santiago: Ediciones Universidad Diego Portales, 2013. 46. 


\section{Mistral, Neruda y los novelistas rusos: 1920}

Han pasado dieciséis años desde aquel 1904. Es 1920, un año, al menos en educación, que tiene gran trascendencia para Chile, pues se dicta por primera vez en el país, el 26 de agosto, la Ley de Instrucción Pública Primaria. Esto resultará un paso importante, pues su objetivo será ampliar la capacidad instalada de escuelas y reducir la deserción escolar (Serrano, Ponce de León y Rengifo 104). En este contexto, ya Gabriela Mistral ha comenzado a ser famosa y renombrada dentro y fuera de Chile por su producción literaria. Pero, a la vez, su labor educacional, hecha con esfuerzo personal, ha tenido resultado palpables en Los Andes, donde ha sido Inspectora General y Profesora de Castellano e Historia; en Punta Arenas, donde por petición del Ministro de Justicia e Instrucción Pública Pedro Aguirre Cerda, dirige el Liceo de Niñas; y ahora, en Temuco, donde vuelve a ejercer de directora justamente en 1920. Ella misma contará, con breves palabras, su experiencia: "El Liceo de Temuco era un caos de luchas internas y desorden cuando el gobierno me mandó allá. He conseguido llevar a él la paz, verdad es que todas las profesoras son tituladas" (Mistral, Vivir y escribir 68). Pero serán otros los que den a conocer su amplia labor social. Dirá, por ejemplo, uno de los compiladores más importantes de su obra:

En esta ciudad, Gabriela desarrolla numerosas actividades: bregó por los más desposeídos; los obreros y los presos a quienes ofrece varias conferencias, en especial, aquellas que dicta en La Casa del Pueblo; se preocupó de la formación de sus niñas del liceo, instaurando políticas en pro del libro, y la formación de nuevas bibliotecas (Zegers 26).

Y es en esta labor donde acontece un encuentro especial entre Mistral y un personaje que le agradece lo que hizo con él. Será un encuentro donde salen a relucir nuevamente los escritores rusos. Allí se topa con el joven -de dieciséis años- Neftalí Ricardo Reyes Basoalto, conocido más tarde en las letras universales como Pablo Neruda. Gabriela Mistral le abriría las puertas de la Biblioteca del Liceo de Niñas. El gran poeta chileno siempre reconocerá la importancia del magisterio recibido de Gabriela en esa época, a la que dedica unas cálidas palabras en su auto-biografía intitulada Confieso que he vivido:

Por ese tiempo llegó a Temuco una señora alta, con vestidos muy largos 
y zapatos de taco bajo. Era la nueva directora del liceo de niñas. Venía de nuestra ciudad austral, de las nieves de Magallanes. Se llamaba Gabriela Mistral [...]. La vi muy pocas veces. Lo bastante para que cada vez saliera con algunos libros que me regalaba. Eran siempre novelas rusas que ella consideraba como lo más extraordinario de la literatura mundial. Puedo decir que Gabriela me embarcó en esa seria y terrible visión de los novelistas rusos y que Tolstói, Dostoievski, Chejov... entraron en mi más profunda predilección. Siguen acompañándome (Neruda 31-32).

Aquí puede entreverse que Gabriela Mistral conoce bien a los novelistas rusos, o por lo menos, los ha leído con deleite y aprovechamiento personal. Han pasado dieciséis años entre 1904 y 1920. En la primera fecha tiene quince años, y en la segunda, treinta y uno. Ha sido un tiempo en el que la lectura de estos autores ha podido dejar una huella imborrable en la poeta. Una huella que ha permitido calificarlos como "lo más extraordinario de la literatura mundial".

La relación de autores que Neruda ofrece, pareciera que es la definitiva: Tolstói, Dostoievski, Chejov... Pero, como veremos a continuación, conoce a muchos otros. Se identifica ideológicamente con varios, lo cual hace constatar que no solo conoce sus escritos, sino también sus vidas. Incluso, podemos adelantar que en alguna de estas vidas tormentosas de los novelistas rusos, Gabriela se ve fielmente reflejada.

\section{Gabriela Mistral comentando a los rusos}

\section{Lectura para mujeres}

Como se sabe, el gobierno mexicano ofrece a la poeta, a los treinta y tres años de edad, integrar la Comisión de Reforma Educativa de México. Reforma dirigida por el filósofo y ministro de educación José Vasconcelos, y que está orientada por una fuerte conciencia de las raíces autóctonas mestizas. Gabriela Mistral se encarga de dirigir las escuelas llamadas "Casas del Pueblo", donde se imparten clases de música, teatro, pintura, escultura, deporte y técnicas agrícolas. La poeta realiza esta labor principalmente en comunidades indígenas (Mistral, Antología de poesía 393). 
La labor de Gabriela Mistral en México fue muy social y positiva. Se le recuerda como una educadora identificada con su labor: "Se integra a las misiones rurales, implementadas por el gobierno mexicano para adentrarse en los sectores más abandonados de la república" (Villegas 4). Pero también se le reconoce su natural humanidad, su liderazgo pedagógico y su modo genuino de tratar a las personas:

Iba a los pueblos. Adoraba a la gente del campo y en seguida se entendía con ella. Hablaba con los maestros, los veía trabajar; hacía para ellos pláticas y conferencias sobre el sentido de la enseñanza, sobre los fines que se perseguían en las nuevas escuelas, sobre el material escolar, sobre la enseñanza de la Geografía y la Historia... sobre los libros para los niños y para los jóvenes, sobre el uso de las bibliotecas, sobre la cultura necesaria al maestro y a la mujer... (Mistral, Lectura para mujeres IX).

En ese espacio mexicano, Gabriela Mistral publica su Lecturas para mujeres. La primera edición es de 1924. Se trata de una completa y profunda recopilación que realiza de lecturas que a ella le parecen pudiesen ser útiles para la cultura femenina. Sabe que las mujeres, por las limitadas oportunidades que tienen en su educación escolar, se quedarán, señala la autora, "sin conocer las páginas hermosas de nuestra literatura. Bueno es darles en esta obra una mínima parte de la cultura artística que no recibirán completa y que una mujer debe poseer. Es muy femenino el amor de la gracia cultivado a través de la literatura" (Mistral, Lectura para mujeres XVI).

Allí, los autores elegidos son organizados por Mistral en tres distinciones: (1) autores que cita, y nada más; (2) otros que cita y aconseja la lectura de algunas de sus obras; y (3) autores que cita y aconseja leer toda su obra. En esta tercera categoría pone a Martí -que cita siete veces-, Tagore, Azorín, Rodó, Amado Nervo, Pedro Prado y Alfonso Reyes, entre otros. En cuanto a los rusos, solamente cita a Tolstói -en la 2-y Máximo Gorki -en la 1-.

De Tolstói ofrece el cuento El perro muerto, en la sesión intitulada "Motivos espirituales", acápite "a", llamado "La caridad". A final de este texto dice Mistral: "Recomendar Cuentos populares y Resurrección, de León Tolstói" (Mistral, Lectura para mujeres 161-162). De Máximo Gorki ofrece el relato La canción del albatros, en la sesión intitulada "Naturaleza", acápite 
"b", llamado "Motivos del mar". Aquí, al final del texto gorkiano, no hace recomendación alguna de lecturas de este autor (265-266).

Estos son los únicos datos escritos que existen sobre las recomendaciones de leer a estos autores rusos. No deja de ser importante que hay alguna intencionalidad pedagógica detrás, pues quiere ofrecer una solución para aumentar la cultura de la mujer a través de la lectura de los mejores autores. Y dado que Gabriela Mistral los conoce muy bien, los ha leído suficientemente, no debe ser casualidad o mera erudición que haya elegido entre estos relatos, uno de Tolstói y otro de Gorki. Además, del primero recomienda otras obras, lo que nos ofrece la idea de que conoce ampliamente sus escritos.

\section{Magisterio y niño}

Magisterio y niño es una compilación editada en 1979 sobre los escritos que ha dejado Mistral en el ámbito de la educación a veintidós años de su muerte. Destaca el prologuista y compendiador, Roque Esteban Scarpa, la visión que Gabriela Mistral tenía del problema educativo: "El conocimiento llega a la mecanización porque quienes lo imparten carecen de ese fervor del espíritu que da vida, y puede trasmitirse como vida, a lo que se sabe. No disocia la profesión del ser" (Mistral, Magisterio y niño 21). Dice también el prologuista, que: "los métodos que [Gabriela Mistral] fue desarrollando los aprendió de la necesidad y la experiencia. En base a sus ideales creó su manera, "suma de las mil voces que le daban los libros». Afirmaba: «La maestra que no lee tiene que ser mala maestra: ha rebajado su profesión a mecanismo de oficio al no renovarse espiritualmente»" (12).

Nuestra poeta está muy clara en la idea de que el maestro no puede caer en el "hacer por hacer" o como ella lo llama, en la "mecanización" del oficio. Y que una forma de que esto no ocurra, es necesariamente leyendo buenas obras, pues estas le pueden "renovar espiritualmente". Es la lectura un hábito indispensable en todo educador si no quiere entumecerse, paralizarse o ser para sus alumnos un mero funcionario que ofrece unos 
conocimientos sin más, sin arte, sin pasión o sin ilusión. La lectura ilusiona al educador, le insufla ánimo y amor genuino por lo que hace.

Con esta presentación de las intenciones de nuestra autora acerca de su visión de la educación es que podemos ahora presentar las veces en que cita y recomienda la lectura de los novelistas rusos. Por eso pensamos que el acercamiento a estos autores es, para Gabriela Mistral, una oportunidad de desarrollo educacional. No puede ser casualidad, como hemos dicho más arriba, que nombre a estos autores solo para mostrar su importancia o su fama literaria. Para la maestra que fue Gabriela, leer y tener a los rusos en las escuelas, tenía importancia pedagógica.

Mistral es una constante promotora de las bibliotecas. Las ensambló y renovó con especial intensidad durante su responsabilidad como directora en Punta Arenas, Temuco y Santiago, entre 1918 y 1922. Y en sus escritos habla con franqueza, con un estilo directo, de lo que deben procurar los buenos bibliotecarios. En el capítulo denominado "Libro y Niño", y dentro de este, en el subcapítulo "Apostolado del bibliotecario", les dice: "[...] los bibliotecarios con sentido de misión pueden lograr que el lector popular reconozca ciertas verdades verticales. El teatro griego, Shakespeare, el Dante, Cervantes, Rabelais, Dostoiewski, Montaigne..." (Mistral, Magisterio y niño 86). Luego, en el capítulo intitulado "Informaciones y posiciones sobre la Educación", y dentro de este, en el subcapítulo "Las bibliotecas populares", vuelve a decir lo que un buen bibliotecario debe lograr en los lectores. Estos deben dar un "salto", que ella denomina "mortal", desde Montepin al Dante. Y que, además, "al lector de mala novela, le llevará, suavemente, desde Montepin hasta Dostoievski" (174).

Llama la atención que en estas dos ocasiones nombre a Dostoievski. Decimos esto porque según lo que hemos revisado hasta el momento, son las únicas dos alusiones directas sobre este escritor que hace la poeta en su obra. Pero, no por ello deja de ser importante que lo haga, porque como se ve, lo recomienda con absoluta seguridad como una lectura que, incluso, debe ser motivada por quienes cumplen funciones dentro de una biblioteca. 
Nuevamente, en el capítulo "Libro y Niño", pero ahora en el subcapítulo "Libros escolares complementarios", hace recomendación de dos autores rusos. Por una parte, La infancia de Máximo Gorki, porque, dice que "está contada para la Rusia y la América nuestra" (Mistral, Magisterio y niño 114); y, por otra, en una postdata de este subcapítulo expresa: "He olvidado las dos lindas novelas de infancia y adolescencia del ruso Garín" (117). Lo anterior muestra que Mistral conoce con bastante amplitud las obras infantiles de algunos escritores rusos.

Regresando al capítulo "Informaciones y posiciones sobre la Educación", y esta vez en el subcapítulo "La reforma educacional de México", la autora hace dos menciones del escritor ruso Tolstói. En la primera ocasión se refiere a unas nuevas publicaciones de lecturas que ella opina dan un equilibro a las ya publicadas, y que pertenecen a autores un poco difíciles de digerir para la lectura. Lo argumenta así: "En verdad, por un Plotino hermético se publicó un Tagore diáfano, por cada Platón un Tolstói evangélicamente popular, con lo cual se hacía el equilibrio" (Mistral, Magisterio y niño 148). Luego, en el mismo capítulo, pero esta vez en el subcapítulo "Cómo se ha hecho una escuela-granja en México", menciona un aspecto de Tolstói que deja entrever que no solo lo conoce como escritor, sino como creador de una experiencia pedagógica propia: "Tenía delante de mí, realizada en la tierra mexicana, la escuela que soñó Tolstói” (163).

Las anteriores son las únicas menciones que Mistral hace de los autores rusos en Magisterio y niño. Parecen ser pocas, pero desde una mirada cualitativa revelan que conoce la jerarquía de estor escritores. Dos veces cita a Dostoievski y Tolstói, y una vez a Gorki y Garín. A todos los sugiere como lecturas importantes a tener en cuenta, pero además, y nos parece significativo, ofrece un dato biográfico de Tolstói, que como veremos más adelante, es guía para la opinión que Mistral tiene sobre la acción que debe desarrollarse al interior de las escuelas.

\section{Diario íntimo y entrevista}

Un dato muy revelador, que arroja luces nuevas sobre la influencia de estos escritores rusos sobre la vida y obra de Gabriela Mistral, es lo que 
ha dejado nuestra autora en uno de sus diarios íntimos y luego en una entrevista. Hay un cuaderno que Mistral intitula "Cuaderno de Varia Lección" y que fue escrito entre 1918 y 1921. Allí expresa: "Los artistas que más han influido en mi vida... son: Tagore, Junqueiro, Andreiev y Martí, entre los modernos [...] En Andreiev he hallado, sí, mi tortura interior..." (Quezada 79). Vemos aquí una identificación directa con este autor ruso en lo relativo a un suplicio interno que tiene nuestra poeta, $\mathrm{y}$ que de alguna manera lo ve reflejado en el artista citado.

Pasemos ahora a una entrevista que realiza Alberto Gerchunoff a Gabriela Mistral en La Nación de Buenos Aires, publicada el 6 de julio de 1925, y que está en la obra Bendita mi lengua sea, de Jaime Quezada, la cual compila apuntes personales de nuestra poeta. En ella vuelve a hablar de su experiencia en México, y dentro de ese contexto cita dos veces a Tolstói. En un primer momento dice:

Iba a los colegios a leer narraciones ejemplares y a resumirlas. Me acuerdo lo que me ocurrió con un relato de Tolstói: nunca pude referirlo dos veces de la misma manera. A medida que lo contaba lo iba modificando hasta convertirlo en una creación particular. Y esto me sucede involuntariamente, por una suerte de necesidad de substraerme a lo que es automático, a lo que puede mecanizarme, y enmohecer mi espíritu (García-Huidobro 172).

Mistral conoce de memoria relatos de Tolstói y, al parecer, ella los acomoda, los complementa, los re-inventa con su propia creatividad para no aburrirse.

En otro lugar de la misma entrevista expresa: “-Comprendo [...] que el Estado no está en condiciones de intentar ni de organizar las escuelas libres, como yo quisiera que fuesen. La escuela de la nación, es decir la escuela moldeadora y colectiva, no puede reproducir lo que crea Tolstói en Jasnaia Poliana o Rabindranath Tagore en el bosque vecino de Calcuta..." (García-Huidobro 173). Aquí ya podemos constatar que no solo conoce los escritos de este ruso, sino, como ya hemos visto más arriba, ofrece un dato relacionado con la forja de una experiencia pedagógica que tuvo cierto renombre, y de la cual hablaremos también más adelante: la escuela 
fundada y dirigida por el propio Tolstói, y que se conoce con el nombre del mismo lugar donde vivía: Yásnaia Poliana.

\section{Tolstói}

Es Tolstói, según la investigación realizada, el autor que más veces cita y comenta Gabriela Mistral. Conoce sus escritos, pero además, conoce su vida, o un aspecto de su vida con el que ella se identifica plenamente: su experiencia como educador. Cuando era directora del Liceo de Niñas de Punta Arenas, enviada allí, como se dijo, por el propio Ministro de Justicia e Instrucción Pública, abrió una escuela nocturna y gratuita para mujeres adultas obreras (Mistral, Vivir y escribir 55-56). En la escuela Yásnaia Poliana de Tolstói, también se dan clases gratuitas para adultos (Tolstoi 44-45). ¿Se inspiraría Gabriela en esta experiencia de Tolstói que iniciaría hacia 1859-1860? Tal vez; y si no se inspiró en él, al menos conoce la experiencia y existe en ella la motivación suficiente para replicarla.

Más arriba hemos visto cómo Mistral sueña con la escuela de Tolstói y luego, sabe que no se puede replicar exactamente como este pretende, pues en Yásnaia Poliana se practica un sistema muy especial, o más bien, un "anti-sistema". Lo relata el propio Tolstói:

Estoy convencido que la escuela no debe intervenir en la educación, pura incumbencia de la familia; no debe castigar ni recompensar lo que ella no tiene derecho, que su mejor policía y administración consiste en dejar a los alumnos en libertad absoluta de aprender y de arreglarse entre ellos como mejor les parezca (25).

Una escuela así, tanto en 1860 como en la época en que Mistral la recuerda - los años 20 del siglo XX -, es un sitio muy especial. En síntesis, Tolstói pretendía con este establecimiento suyo: (a) que hubiese una genuina preocupación por el hombre; (b) un genuino espíritu de libertad; (c) una condena del dogmatismo; (d) una clara repulsa del autoritarismo; (e) un vitalismo existencial frente al mero intelectualismo; y (f) una verdadera educación social-popular (Tolstoi 8). Tolstói, en el fondo, tiene un deseo: "fundar una escuela para los campesinos... donde él mismo les enseñaría a leer y a escribir" (Ríos 48). Todo lo anterior coincide con la labor 
educacional de Mistral. No solo lo que hace en Chile al dirigir sus tres escuelas en Punta Arenas (1918-1920), Temuco (1920) y Santiago (19211922); también lo que pone en práctica en México al ser la responsable de las escuelas llamadas "Casas del Pueblo", donde se impartín, como ya apuntábamos, clases de música, teatro, pintura, escultura, deporte y técnicas agrícolas en comunidades indígenas y campesinas.

Mistral y Tolstói coinciden. Ambos son escritores y ambos son educadores. El binomio perfecto. La conexión espiritual y de genios perfecta. Pero Mistral sabe que la utopía Tolstoyana es difícil de cumplir a cabalidad también en pleno siglo XX. Ella se adapta, pero lucha. Lo que Tolstói ha realizado la motiva e inspira, pues nuestra poeta tiene una gran sensibilidad social, y en sus escuelas $-\mathrm{y}$ en los proyectos que implementa al interior de estas- ofrece su visión humanista y redentora de la educación con esa veta Tolstoyana. Tanto, que a veces lo celebra y lo dice vox populi: "Obtuve otro gran triunfo, conseguí que las familias distinguidas de Punta Arenas no temieran ver confundidas en el liceo a sus hijas con las niñas humildes que asistían en gran número" (Mistral, Vivir y escribir 119).

\section{Gorki}

Ya hemos visto que Mistral recomienda obras de Gorki. Es el otro autor que cita numerosas veces. Incluso lo disfruta a fondo. En una carta que le dirige a Juan B. Contardi, con fecha 18 de abril de 1919, expresa: "Lo he recordado mucho estos días, leyendo una obra recién traducida de Gorki: La madre. Es como el génesis de la rev. Rusa (sic) y es la lectura que me ha removido más en el último tiempo" (Scarpa 350). Se trata de una lectura que moviliza a Mistral por dentro. Creemos que la impacta tanto, que la lleva a conocer lo que está detrás del autor: su vida.

Según el historiador Pablo Schostakovsky, Gorki es un escritor de los que pertenecen y son fieles a la revolución bolchevique. Se le tilda como el cantor de los "descalzos", y su reputación política ha estado siempre por encima del valor artístico de sus obras, en donde se consagra, por ejemplo, describiendo vagabundos andrajosos (Schostakovsky 454). 
Gabriela lo conoce bien. Tanto, que el 15 de noviembre de 1936, a raíz de su muerte, escribe un artículo en El Mercurio de Santiago que intitula "Recado sobre Máximo Gorki". El artículo está lleno de muchos detalles biográficos. Por ejemplo, que su apellido en ruso significa "amargo" o "desgraciado", lo cual usa la poeta para reafirmar la infeliz niñez que vivió Gorki. También por el artículo sabemos que su madre no influye nada en este niño y que su padre los abandona tempranamente. Un abuelo le enseña y dicta los Salmos del Rey David, y lo encauza a la escuela a la que solo asiste por cinco meses. Se trata, al final, de un hombre absolutamente autodidacta que llegará a ser, durante la Rusia soviética, Ministro de Bellas Artes.

Podríamos decir que hay una especie de paralelismo entre la vida de Mistral y la vida de Gorki en al menos tres aspectos: el primero, el abandono de uno de los progenitores; en el caso de Gabriela su padre la deja cuando esta tiene tres años. Lo segundo, es la abuela paterna de Gabriela quien le da a leer la Biblia; en Gorki es su abuelo materno quien le da a leer los Salmos de David. Lo tercero, el autodidactismo; Gabriela se forjó a sí misma durante toda su vida; y además, no obtuvo un título completo de maestra normalista -solo se le reconoció su práctica-, lo que suscitó protestas cuando se encargó de la dirección de sus colegios. Esto la hará sufrir.

Aunque Mistral no fue atea ni marxista como sí lo fue Gorki, se identifica plenamente con este autor por aquellos sucesos o procesos vitales en los que coinciden. Es probable que la poeta encontrara ánimo e inspiración en un escritor famoso y, además, ruso, quien ha sufrido tanto como ella. A veces los seres humanos necesitan parecidos para auto-motivarse y seguir adelante. Es natural identificarse con alguien que ha padecido lo mismo. Gabriela se apoya en la vida de Gorki: escritor, huérfano de padre y autodidacta. Es su espejo. Y ambos tienen la misma pasión: escribir. Pero Gorki no será el único.

\section{Andreiev}

De este autor, como ya lo dijimos en líneas precedentes, hace un comentario Gabriela Mistral que es bien llamativo. Volvemos a traerlo aquí para entrever qué puede haber de fondo. Por una parte, dice nuestra autora que Andreiev 
es uno de los artistas, entre los modernos, que más han influido en ella, y a continuación expresa: "[...] en Andreiev he hallado, sí, mi tortura interior...”. ¿Qué significará para Gabriela Mistral haber encontrado su tortura interior en Andreiev? Para responder a esta pregunta hay que conocer muy bien la vida de Mistral, y además, desentrañar la de Andreiev. No es objeto de este trabajo tener a la mano todos los detalles de estas biografías, pero nos suscribiremos a algunos autores para ver dónde existen coincidencias, o en dónde podemos encontrar alguna señal que nos permita entender esa "tortura interior" con la que ambos están alineados.

Según el historiador Pablo Schostakovsky, Leonid Andreiev (1871-1919) es uno de los escritores más talentosos de su generación. Al principio será realista, pero luego pasa a la imaginación pura. Todos sus personajes mueren de muerte violenta, y si nadie los mata, se suicidan. Tanto miedo quiere mostrar Andreiev, que el mismo Tolstói dirá: "Andreiev quiere asustarme, pero yo no me asusto" (ctd en Schostakovsky 407-408).

En sus Obras Escogidas, recopiladas y traducidas por el crítico literario Rafael Cansinos Assens, quien además ofrece un estudio preliminar de su vida, se pueden encontrar algunas luces. Por ejemplo, se sabe que la vida de Andreiev es bastante desconocida. Máximo Gorki escribe una biografía de él que está perdida. Solo se conoce en líneas generales que nació en la pobreza en un hogar humilde. Tuvo una infancia de huérfano, una juventud trabajosa y difícil, con conato de suicidio. Fue un hombre que sufrió y tuvo rasgos depresivos. Experimentó breves años de éxito internacional. Pero murió en una oscura aldea de Finlandia como refugiado político, fugitivo de la revolución bolchevique. En esto, es dato conocido que odiaba a la revolución, la cual tildaba de "demagógica” (Andreiev 9-14).

En la misma exposición que Cansinos Assens realiza sobre su vida, destacan algunas frases llamativas. Por ejemplo, "la vida de Andreiev es ella misma un símbolo amargo de la vanidad de las ilusiones" (9). Y que, a pesar del éxito, Andreiev "sigue viendo la vida con los mismos ojos tristes de su infancia" (12). Pero además, no resiste la revolución. "Ante la dictadura del proletariado, su espíritu independiente, individualista, sublevábase como ante la dictadura zarista" (13). 
Tenemos pues, un escritor ruso con esa "tortura interior" que señala Gabriela Mistral, y en la que ella también parece que se encuentra reflejada. "Al acompañar los relatos de Gabriela Mistral acerca de sus distintas experiencias vitales y laborales, podemos reconocer que el dolor parece ser un elemento común y hasta movilizador en distintas situaciones" (Sepúlveda 295).

En 1900, con apenas once años de edad, le sucede algo que nunca olvidaría, algo que evidentemente marca cualquier infancia. Gabriela, en ese entonces con su verdadero nombre de Lucila Godoy, entra en la escuela primaria de Vicuña. La directora se llamaba Adelaida Olivares y era ciega, por lo que toma a Gabriela de lazarillo. Pero además, tiene otro encargo: se le ha confiado la tarea de distribuir los útiles escolares, específicamente los cuadernillos con líneas o cuadriculados que tenían impreso su origen y destino como "Oficinas Fiscales". Pues bien, un día se perdió uno de estos cuadernillos y Gabriela fue acusada del robo. La directora quiso colocar una sentencia que de alguna manera cubriera el oprobio. Anota en el diario de la escuela: expulsada por "débil mental". Gabriela, al salir del establecimiento el día de su expulsión, en la Plaza de Vicuña, es esperada por sus excompañeras de colegio. Pero no es una espera alegre, pues están repletas de piedras que lanzan a la expulsada, dejándola llena de sangre. Gabriela, apedreada y humillada, puede huir despavorida (Teitelboim 23$)^{5}$.

También se sabe de un incidente incierto relatado por la misma Mistral, sobre algo que le pasó en esa misma población de Vicuña. No se sabe si fue antes o después del anterior hecho con las compañeras de escuela. Al parecer, un joven quiso abusar físicamente de ella. Expresa la poeta con viva tristeza: "me encontró sola, se le desataron los instintos bestiales" (Ladrón de Guevara 99).

En 1907, a los dieciocho años, Gabriela experimenta otra situación, no del mismo tenor anterior, pero muy incómoda. En el Liceo de Niñas de la Serena ha conseguido un puesto de secretaria. Pero entra en constante

5 Es interesante saber que Luis Vargas Saavedra en el Prólogo a la Antología Mayor, comenta que este incidente carece de veracidad histórica por no existir testimonios de testigos o datos en la prensa local. Véase: Mistral, Gabriela. Antología Mayor. Santiago: Cochrane, 1992. XI. 
tensión con la directora, la alemana Ana Krushe, con quien tiene numerosos desencuentros y choques. La gota que derramaría el vaso sería que Mistral matriculaba a niñas que por su condición social no podían pertenecer al Liceo. Esta vez, y para no seguir con los desencuentros entre ambas, secretaria y directora, es obligada a renunciar (Manzano 145).

En 1903 conoce a Romelio Ureta, que es empleado en el ferrocarril del Norte. Su trato con este joven se intensifica hacia 1907. Pero en 1909, Romelio se suicida. Ya no eran novios, pero en sus bolsillos hay una tarjeta de Lucila Godoy. Sin embargo, no se atribuye al suicidio una causa sentimental sino de honor: un préstamo de dinero proveniente de las cajas del Ferrocarril que no puede devolver. De este trágico incidente escribe Los sonetos de la muerte, haciéndola merecedora de la más alta distinción en los Juegos Florales de Santiago en diciembre de 1914 (Manzano 44-46). He aquí algún verso de ese hermoso poema trágico:

Del nicho helado en que los hombres te pusieron, / te bajaré a la tierra humilde y soleada. / Que he de dormirme en ella los hombres no supieron, / y que hemos de soñar sobre la misma almohada. / Te acostaré en la tierra soleada con una / dulcedumbre de madre para el hijo dormido / y la tierra ha de hacerse suavidades de cuna / al recibir tu cuerpo de niño dolorido. [...] Sentirás que a tu lado cavan briosamente, / que otra dormida llega a la quieta ciudad. / Esperaré que me hayan cubierto totalmente... / iY después hablaremos por una eternidad! (Mistral, Desolación 124-125).

En Punta Arenas, entre 1918 y 1920, cuando dirigía el Liceo de Niñas, Gabriela Mistral va a expresar momentos difíciles por los que pasa: aunque estaba entusiasmada, no era del todo fácil dirigir un centro escolar en un lugar tan lejano, inhóspito, frío y solitario. Escribiría que: “[...] siempre soplaba un viento agudo y frío por todos lados; se le oía pasar desbocado por las noches y en el día era necesaria una buena dosis de valor para soportarlo. Nieve, humedad, viento; sentía que me doblaba..." (Mistral, Vivir y escribir 110). Y también relataría que cierto grado de depresión la invadía en ocasiones: "tenemos feriado hasta el lunes. Me he quedado en cama, porque he tenido una de mis congestiones cerebrales, leve, leve. Días de enorme depresión espiritual, que no sé si achacar al invierno que empieza o a los contratiempos del colegio" (ctd en Quezada 68). 
Entre 1921 y 1922, Gabriela sufrió cierta animadversión entre sus propios colegas educadores chilenos. Especialmente cuando fue directora del Liceo de Niñas Nro. 6 de Santiago. Ella misma lo cuenta: "mientras viví en provincias me perdonaron la dirección del Liceo; en Santiago, no. Jamás mi gremio profesional me perdonará mi falta de título" (ctd en Quezada 68).

Otro dato que ofrece un cuadro de los estados de ánimo de Gabriela Mistral es su primera obra, Desolación, cuya primera publicación es en 1922. Incluye allí poemas de una amargura aguda. Ya hemos hablado de "Los sonetos de la muerte", pero también pueden conocerse "El ruego", "Poema del hijo" y "Los huesos de los muertos" (Mistral, Desolación 140, 142 y 149). De hecho, llama la atención la nota con que termina esta obra:

Dios me perdone este libro amargo y los hombres que sienten la vida como dulzura me lo perdonen también. En estos cien poemas queda sangrando un pasado doloroso, en el cual la canción se ensangrentó para aliviarme. Lo dejo tras de mí como a la hondonada sombría y por laderas más clementes subo hacia las mesetas espirituales donde una ancha luz caerá, por fin, sobre mis días (Mistral, Desolación 140).

Lo anteriormente presentado, da datos suficientes de la vida agitada y marcada por sufrimientos de nuestra poeta. ¿Puede esto confirmar que Gabriela sufrió tanto como para expresar que tenía una "tortura interior", y que en un escritor ruso como Andreiev pudo hallar un espejo de consuelo? Creemos que sí podemos aseverarlo.

Gabriela nace en un lugar muy pobre y tiene también una infancia de la misma condición, tal cual como Andreiev. Sería huérfana de padre al igual que el ruso. Convivió con el suicidio de otros a quienes amaba: un exnovio, y más adelante, unos amigos muy cercanos en 1942, y un sobrino a quien criaba como hijo propio en $1943^{6}$. Tampoco sabemos que haya

6 En 1926, el hermano de su padre, viudo reciente, le va a pedir que se encargue de la crianza de su hijo de meses, Juan Manuel, mejor conocido luego como "Yin Yin". En 1943, siendo Gabriela Cónsul de Chile en Brasil y residente en Petrópolis, Yin Yin muere trágicamente a los dieciocho ańos. La policía del lugar presenta pruebas de suicidio con arsénico, pero la poeta sostiene que ha sido víctima de una banda de jóvenes neonazis de color, por su rechazo 
sido depresiva habitual, pero pudo haberlo estado en alguna ocasión, como de hecho lo vimos en Punta Arenas. Según sus biógrafos, Andreiev era depresivo. Gabriela tampoco fue perseguida, pero sí incomprendida por su propio gremio chileno al no tener título superior. Andreiev fue perseguido por una revolución de sus propios compatriotas, lo cual lo llevó a morir fuera de Rusia. Gabriela murió en Estados Unidos.

No hay duda de que hay coincidencias. Es entendible que las torturas compartidas, de alguna manera, ayuden a mitigar el peso que representan. Gabriela Mistral conoce la vida de Andreiev y sabe que hay mucho paralelismo, analogía, algún grado de similitud. El encontrarse con otros a quienes les pasa lo mismo puede ayudar a dar perspectiva y sentido, pues se puede caer en la cuenta de que no estamos tan solos en el mundo. Las penas compartidas se vuelven menos penas. Así, Andreiev se convierte en esa otra tortura que acompaña y mitiga las torturas de la propia Gabriela Mistral en su vida. Son dos interioridades que teniendo la misma profesión de escritores, comparten el mismo destino: el sufrimiento.

\section{Conclusiones}

Un biógrafo de Gabriela Mistral, Volodia Teitelboim, describe un episodio de su biografiada que parece - dice el autor - arrancado de una página de Dostoievski en Pobres gentes de un cuento de Antón Chejov. Relata que Gabriela muchos años después, ya en plena fama, regresa a Vicuña como en fugaz visita a los espacios de su infancia. Al llegar se cruza con un funeral. Se deja arrastrar y se adentra en las filas del mismo, como si fuera

a unirse a ellos, su situación privilegiada y su tez blanca. Por este suceso, Gabriela cae en un estado de tristeza enorme, que incluso hace cambiar radicalmente su rutina diaria, dejando de lado su escritura habitual y recibiendo una poquísima cantidad de visitas, de las muchas que solía recibir en su casa. En esta misma ciudad, ya Gabriela había sufrido un año antes, en 1942, el también lamentable deceso de su amigo el escritor austríaco Stefan Zweig, quien junto a su esposa, decide suicidarse. Esto la dejó desbastada. Véase: Zegers, Pedro Pablo, Prólogo a la edición de: Mistral, Gabriela. Yin Yin. Santiago: Ediciones Universidad Diego Portales, 2015. 21-22. 
un familiar del muerto. Parece que intuyó que aquel entierro tenía algo que ver con ella. Llegó con el féretro hasta la iglesia. Una niña le entregó unas flores, igual que a los otros acompañantes del duelo. Se percató que tales flores eran para depositarlas sobre el ataúd. Las colocó haciendo una lenta y devota reverencia, musitando un rezo. Luego preguntó de quién era aquel cuerpo de mujer fenecida. -Doña Yaya, le dijeron. Doña Adelaida Olivares. Era una señora ciega. Directora de una escuela. Le preguntaron: -cंse acuerda de ella?-. Respondió secamente: -Yo no olvido nunca (Teiltelboim 23-24).

Resultan sorpresivas las tantas coincidencias entre la vida de Gabriela Mistral y la vida de algunos novelistas rusos. Cualquiera de ellos, o más cercanamente Gorki y Andreiev, coinciden en sus vidas con lo que Gabriela ha sufrido. "Niña pobre, niña abandonada por su padre - dirá Leila Guerriero en el prólogo a Desolación-, niña hija de madre con dos hijas pero sin marido, niña india, niña fea, niña sin estudios" (Mistral, Desolación 19). Lo mismo podríamos decir de ellos, con solo algunos cambios menores.

Algunos novelistas rusos dieron a Gabriela Mistral perspectiva a su propia vida. Le ofrecieron la oportunidad de entender que no estaba sola en el mundo. Que había otros escritores, soñadores, artistas, que también tuvieron limitaciones y mundos interiores tortuosos. Fueron su espejo. Fueron su apoyo. Los leyó, pero además los conoció a fondo. Indagó en ellos lo que tenían de parecido con ella.

Pero no solo se identificó en el sufrimiento de estos. También halló ideales que ella buscaba, ofrecía y vivía. Ella amó a los pobres, a los campesinos, a los desposeídos. Lo mismo encontró en Tolstói y Gorki. Y aún más. Ella amó lo rural, y en Tolstói pudo encontrar inspiración. Y mucho más todavía. Ella dedicó muchos años de su vida a la educación, y en Tolstói encontró lo que ella también buscaba: una escuela sin castigos, una escuela sin normas, una escuela para fomentar la lectura, y una escuela para enseñar a los analfabetos y dar clases a los adultos sin educación.

Pero además, en los novelistas rusos se vio retratada, porque ella los leyó y aprendió de la ingenuidad, la humildad y la franqueza de estos escritores. 
"Escribir no podía ser para ellos un pasatiempo, ni una profesión lucrativa, ni una vanidad, sino una misión, a veces dolorosa, que pedía, ante todo, abnegación" (Schostakovsky 9). En esto, nuestra autora se parece plenamente. Su vida no fue otra que la de escribir abnegadamente y con esa experiencia vital que siempre la caracterizó. Para los rusos "la literatura es vida, y si no es vida no es nada” (Schostakovsky 8). De Gabriela Mistral se puede decir lo mismo. Su escritura fue la vida que experimentó.

Algunos novelistas rusos influyeron en la vida y obra de Gabriela Mistral. No de un modo que pueda decirse que es plenamente palpable. Mistral “dejó miles de cartas, cientos de artículos, decenas de conferencias, y dijo mucho y sobre todas las cosas: sobre la paz, sobre la guerra, sobre José Martí, sobre Nicaragua, sobre Sandino, sobre Dios, sobre los hombres, los niños, las mujeres, los maestros, los indios, los pobres, la poesía, la educación, los campesinos" (Mistral, Desolación 45). De todo esto, solo hemos podido revisar un diminuto espacio de la vida y obra de nuestra autora. De ahí que hemos acompañado al título de este artículo con un epíteto: una aproximación. Aproximarse es acercarse, juntarse, arrimarse un poco más. Habría que acercarse muchas más veces para encontrar otras nuevas dimensiones de la relación de Gabriela Mistral con estos gigantes de la literatura universal.

\section{Lista de referencias}

García-Huidobro, Cecilia. Moneda dura. Gabriela Mistral por ella misma. Santiago: Catalonia, 2007.

Ladrón de Guevara, Matilde. Gabriela Mistral, rebelde magnífica. Santiago: Editorial Emisión, 1980.

Mistral, Gabriela. "Recado de Máximo Gorki”. El Mercurio 15 de nov. 1936. . El oficio lateral [manuscrito]. Santiago. 1949. Archivo de la Biblioteca Nacional de Chile. Catálogo bibliográfico. . Magisterio y niño. Santiago: Editorial Andrés Bello, 1979. . Antología Mayor. Santiago: Cochrane, 1992. - Antología de poesía y prosa de Gabriela Mistral. Santiago, Fondo de Cultura Económica, 1997. 
. Lecturas para mujeres. México: Porrúa, 2005.

- Vivir y escribir. Prosas autobiográficas. Santiago: Ediciones Universidad Diego Portales, 2013.

. Desolación. Santiago: Ediciones Universidad Diego Portales, 2014.

. Yin Yin. Santiago: Ediciones Universidad Diego Portales, 2015.

Neruda, Pablo. Confieso que he vivido. Santiago: Pehuén Editores, 2005.

Quezada, Jaime. Bendita mi lengua sea. Diario íntimo de Gabriela Mistral. Santiago: Planeta-Ariel, 2002.

Santiván, Fernando. Memorias de un Tolstoyano. Santiago: Zig-Zag, 1955.

Scarpa, Roque Esteban. La desterrada de su patria. Vol. II Santiago: Nascimento, 1977.

Zegers, Pedro Pablo. Recopilación de la Obra Mistraliana 1902-1922. Santiago: Ril editores, 2002.

Alegría, Fernando. Genio y figura de Gabriela Mistral. Buenos Aires: Editorial Universitaria de Buenos Aires, 1966.

Álvarez Pavez, Pedro. "Bernardo Ossandón Álvarez". Liceo Comercial A-6 Bernardo Ossandón Álvarez, Coquimbo. 24 de nov. 2015 <http:// www.isccoquimbo.cl/utp/descargas/Biografia_Bdo_Ossandon Alvarez.pdf $>$

Andreyev, Leonid. Obras escogidas. Madrid: Aguilar, 1963.

Biblioteca Nacional, Dirección de Bibliotecas, Archivos y Museos. Gabriela Mistral. A cien años de su nacimiento. 1889-1989. Santiago. 1989.

Domínguez, Héctor. "La intimidad homosocial en Memorias de un Tolstoyano de Fernando Santiván". Acta Literaria 33 (2006): 41-54.

Egaña, María Loreto; Núñez, Iván; y Salinas, Cecilia. La educación primaria en Chile: 1860-1930. Una aventura de niñas y maestras. Santiago: LOM, 2003.

Fuentes, Miguel. "Educación popular en la sociedad de artesanos de La Serena: Escuela Nocturna 1874-1884". Revista UINIVERSUM. 24.1 (2009): $42-57$.

Galgani, Jaime. "Recepción de la narrativa social europea en Chile (18801920)”. Literatura y lingüística. 22 (2011): 15-27.

. "La Colonia Tolstoyana: Síntesis de las tendencias artísticas de inicios del siglo XX”. Acta Literaria 32 (2005): 55-69. 
Manzano, Rolando. Gabriela en Coquimbo. La Serena: Editorial de la Universidad de La Serena, 2015.

Melfi, Domingo. Estudios de literatura chilena. Santiago: Nascimento, 1938.

Mayorga, Rodrigo. "Los conceptos de la escuela: aproximaciones desde la historia conceptual al sistema educativo chileno. 1840-1890". Revista de historia social y de las mentalidades 15.1 (2011): 1144.

Ocampo, Javier. "Gabriela Mistral la maestra de escuela, premio Nobel de literatura". Revista de Historia de la Educación Latinoamericana 4 (2002): 221-246.

Ponce de León, Macarena. "La llegada de la escuela y la llegada a la escuela. La extensión de la educación primaria en Chile, 18401907". Historia 43.2 (2010): 449-486.

Ríos, Antonio. Lev Tolstoi. Madrid: Rialp, 2015.

Rioseco, Juan. "Utopía y Comunidad: Dos proyectos de vida comunitaria a comienzos del siglo XX en Chile”. Revista Pléyade 5 (2015): 93112.

Schostakovsky, Pablo. Historia de la literatura rusa. Buenos Aires: Losada, 1945.

Sepúlveda, Carola. "Gabriela Mistral: tácticas de una maestra viajera". Revista colombiana de educación 61 (2011): 281-297.

Serrano, Sol; Ponce de León, Macarena; y Rengifo, Francisca. Historia de la educación en Chile (1810-2010) Tomo II, La educación nacional (1880-1930). Santiago: Taurus, 2012.

Teitelboim, Volodia. Gabriela Mistral, pública y secreta. Santiago: Editorial Sudamericana, 1996

Tolstói, León. La Escuela de Yásnaia Poliana. Barcelona: El Barquero, 2003.

Tzitsikas, Helena. Fernando Santiván. Humanista y literato. Santiago: Nascimento, 1971.

Villegas Astudillo, Reinaldo, "Gabriela Mistral en la revolución educativa mexicana”. Odiseo. Revista electrónica de pedagogía 2.3 (2004): $1-6$. 